\title{
A Classification of Japanese Nursing Homes on the Spatial Layouts of Common Facilities: An analysis using Space Syntax Theory
}

\author{
Lin Bai ${ }^{1}$, Miao Cao ${ }^{2}$ \\ 1 Dr. Eng. Research fellow, Institute for Advanced Social Science, \\ WASEDA University, Japan \\ 2 Dr. Eng. Lecturer, Dept. of Architecture, \\ Tohoku Institute of Technology, Japan \\ bailinkylin@gmail.com,,caomiao@tohtech.ac.jp
}

\begin{abstract}
This article analyzes the spatial layout in Japanese nursing homes, and to clarify the core space and spatial characteristics of the common facility. By using the Space Syntax DepthMapX tool, we analyzed 62 nursing homes from Japanese architecture publications. Then, we use the spatial integration metric to identify the core space and transition of the common core facilities. The result shows the core space changed from the corridor in the 1980s to the hall nowadays; the community space and physical training room have also become the common core facility in Japanese nursing homes.
\end{abstract}

Keywords: Common Space, Core Space, Nursing Home, Space Syntax, Depth Map.

eISSN 2514-751X (C) 2021. The Authors. Published for AMER ABRA by E-International Publishing House, Ltd., UK. This is an open-access article under the CC BY-NC-ND license (http://creativecommons.org/licenses/by-ncnd/4.0/). Peer-review under responsibility of AMER (Association of Malaysian Environment-Behaviour Researchers), ABRA (Association of Behavioural Researchers on Asians/Africans/Arabians) and CE-Bs (Centre for Environment-Behaviour Studies), Faculty of Architecture, Planning \& Surveying, Universiti Teknologi MARA, Malaysia.

DOI: https://doi.org/10.21834/ajebs.v6i18.379 


\subsection{Introduction}

Along with the rapid progress of the ageing society in Japan, more elderly would move to nurse homes, which leads to the increasing importance of spatial structure in nursing homes, particularly the shared(common) facilities, because they are closely related to residents' social life.

But what are the characteristics of spatial structure in Japanese nursing homes? Especially after the nursing homes were transited from large-scale care type to unit care type in the 2000s(Murakami, 2011), what spatial structure had been changed? What had happened to shared facilities like community space, physical training room, service station, and dining room by this transition?

A quantitative mean and spatial metric would be helpful to provide the answer and identify the transition of spatial structure in Japanese nursing homes in the past 35 years and is also beneficial to provide the data for future spatial structure design in Japanese nursing homes. The research on the characteristics of the spatial structure by Koike, Ueno, Takano, et al. demonstrated that the Space Syntax(abbreviated as SS) theory is an effective tool to quantitatively evaluate the spatial characteristics in public buildings such as a museum, train station, shopping mall, etc.(Koike, 2011; Ueno, 2008; Takano, 2010). Therefore, in this paper, we selected 62 nursing homes that were built in the year from 1978 to 2014 from Japanese architecture publications(Note 1) and applied the SS theory to analyze the characteristics of spatial structure including the shared facilities such as community space, physical training room, service station, and dining room, to provide an understanding of the spatial characteristics and changes of the spatial layout of shared facilities in Japanese nursing home in the past 35 years.

Based on the care service scale, we categorized the selected nursing homes into largescale care type $(\mathrm{L})$ and unit care type $(U)$. In the large-scale care type nursing homes, the residents share multiple bedrooms, and care services are done on large scale. In the unit care type, the residents own private bedrooms and the care services are done in separate care units. Figure 1 is the selected nursing homes by care type and the build year.

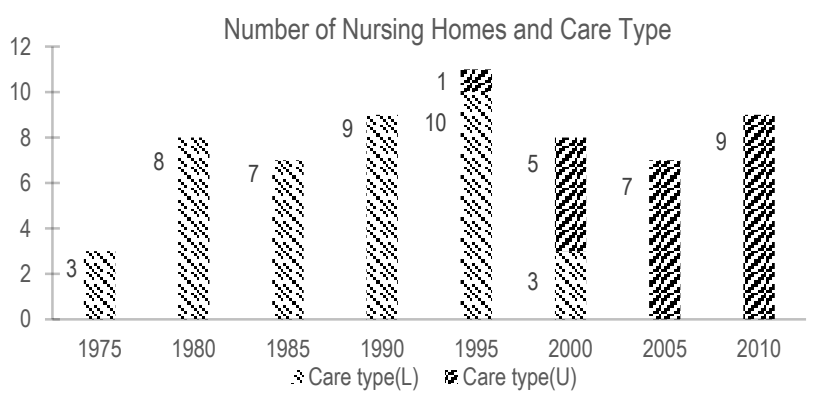

Figure 1: Number of Nursing Homes and Care Type by Construction Period (Source: created by author) 


\subsection{Literature Review}

The spatial structure of the shared facility is a study of concern in Japanese nursing homes. There is much research reported so far. However, most of the studies focused on the impacts of common space on residents' social life. By observing resident environmental behaviour or interview resident daily activities, these studies verified the utilization and importance of shared space to resident social life. The researches done by Inoue, Kato, Mori S., Kozuma, Toyoma, Murakami, and Mori K are typical examples of these studies(Inoue, 1990; Kato, 2007; Mori S., 2007; Kozuma, 2015; Toyoma, 2002; Murakami, 2003; Mori K., 2014).

By analyzing the actual utilization status and based on the behaviour observation for over 50 residents in 3 nursing homes, Inoue put forward the topic of the necessity of having common facilities in the nursing home(Inoue, 1990). Kato researched factors to improve residents living quality(Kato, 2007). Further, by the analysis of actual care activities and people's movement in shared space, Mori pointed out the problem in current nursing home common space designing that some of the care functions which should perform in the common area were packed into a private room(Mori S., 2004). Kozuma proposed a living space layout rearrangement to improve residents' stay and routines of movement(Kozuma, 2015). Moreover, by clarifying the essential elements in residents' daily life and environment, Murakami proposed a common area plan design(Murakami, 2003). Mori explored the design flexibility of dining room space based on the investigation on resident diversity use of dining room space(Mori K., 2014). Besides, Kan.S conducted space syntax analysis on four Japanese nursing homes, concluded to widen the facility and front room hall to secure communication within residents(Kan, 2012).

Although these studies investigated the effectiveness of shared space in affecting resident living quality, the research results didn't provide systematic spatial characteristics of common areas. The research methods were mainly limited to environmental behaviour observation and interviews on resident daily activities. Kan.S applied SS theory to analyze spatial characteristics in nursing home facility hall(Kan, 2012), but the study was limited on the hall's visible scope. Further, the ISOVIST research method was based on the panoptical view scope. It is helpful for wayfinding in the urban fabric but is ineffective in evaluating spatial characteristics in relatively small spaces like inside nursing home buildings and with complex route connections(Nes A.,2012). Also, the research was from only four nursing homes; it did not provide comprehensive characteristics of spatial structure for most nursing homes in Japan.

\subsection{Methodology}

\subsection{Method and Measure}

We applied the Space Syntax theory in this study. The approach quantifies and analyzes the properties of architectural space by a set of spatial attributes: connectivity, depth, and integration(Hillier, 1996).

The depth measures topological steps(turnings) from one space to another, its value is 
one for immediate neighbour space.

The integration expresses the relative depth of one space from the others. It is a fundamental indicator of spatial centrality, which can predict the pedestrian use of the space: the higher integration of a place, the greater centrality of this space within others, and the easier of people to get together in there(Dettlaff, 2014). It is the primary metric to describe the characteristics of the spatial structure of Japanese nursing homes in this research.

Besides, the connectivity attribute measures the number of immediate neighbours that directly connect to the area. It reflects the available access routes; the higher connectivity of the space, the more paths there are to this space.

UCL DepthMapX, the computer tool deployed by SS theory, provides different approaches to calculate space characteristics(Varoudis, 2013). One of the approaches in SS theory is the convex map which utilizes vertical boundaries to convert 3D space to some fattest or largest 2D convex map(also referred to as a convex polygon) and establishes the connection based on the availability of direct access(Peponis, 2002; Klarqvist, 1993). Because it is suited for defining spatial structures such as building interiors more than the visual scope like in the ISOVIST method(Daniel, 2013), we applied the convex map method in this article for spatial characteristics analysis.

The floorplan of each selected nursing home is scanned and converted to an AutoCAD file, which is then imported to the DepthMapX tool to create convex maps. Based on the space function, each space unit is presented by one or multiple convex maps and uses the least number of the convex map to cover all the units. The wall, any partition which separates spaces, is taken as a boundary while doors and openings are connection points. For multi-story buildings, all common facility floorplans are analyzed, where the elevators and staircases are connection points.

However, it should be aware that this analysis method abstracts space to a 2D graph, and the analysis is performed on the morphological structure of the charts, which neglects precise space location(Dawes, 2013).

\subsection{Core Space and Common core Facility}

In this article, the space with the highest integration value is referred to as core space. And, among all common facilities, the community space, the service and care station, the dining room, and the physical training room(such as rehabilitee room, fitness club) are four main common facilities which are usually frequently used in resident's daily life. We mainly analyze these four common facilities. Hereafter, we refer to the space occupied by them as shared(common) space.

Further, to analyze the common space transition, the common facility with the highest integration value is referred to as the common core facility.

\subsection{Findings and Discussion}

\subsection{Analysis of Nursing Home Core Space}


Based on the floorplan of each nursing home, the core space is analyzed. The result tells following area corresponds to the core space in a Japanese nursing home.

A. Corridor - the main or long corridor in a nursing home.

B. Connection corridor - the corridor which links different facility areas such as two care units in unit care nursing home.

C. Hall - the entrance hall, reception lobby, lounge, and EV hall, etc.

D. Common facility - it includes the community space, physical training room, dining room, and service station.

E. Other - all other spaces like the staircases, terrace, etc.

Table 1 and Figure 2 show the number of nursing homes grouped by each core space and the distribution.

Table 1: Number of the nursing home by different kind of core space (Source: Created by author)

\begin{tabular}{ccccccc}
\hline Build period & Corridor & $\begin{array}{c}\text { Connect } \\
\text { corridor }\end{array}$ & Hall & $\begin{array}{c}\text { Common } \\
\text { space }\end{array}$ & Other & Total \\
\hline 1975 & 2 & & 1 & & & 3 \\
1980 & 6 & & 2 & & & 8 \\
1985 & 4 & & 3 & & 2 & 7 \\
1990 & 5 & & 2 & & 2 & 11 \\
1995 & 5 & 2 & 3 & 1 & & 8 \\
2000 & 2 & 1 & 2 & 3 & & 7 \\
2005 & & 3 & 2 & 2 & & 9 \\
2010 & & 4 & 5 & & & 62 \\
\hline Total & 24 & 10 & 20 & 6 & 2 & 6 \\
\hline
\end{tabular}

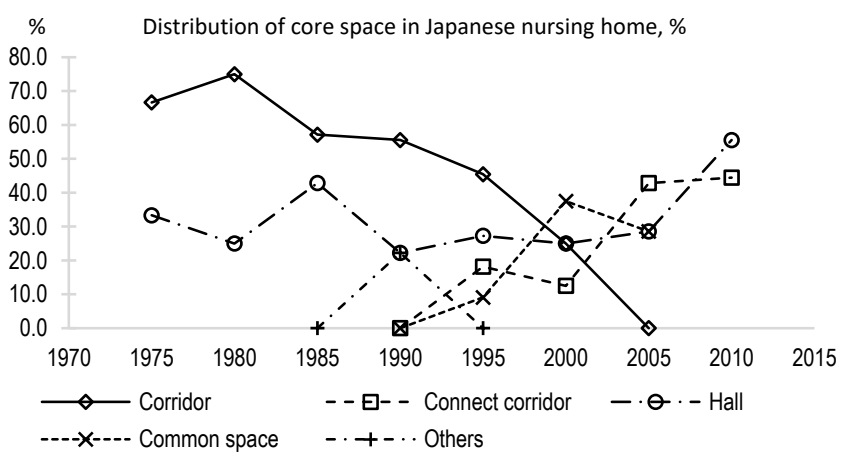

Figure 2: Distribution of core space in Japanese nursing home

(Source: created by author)

Figure 2 tells that the central core space has been changed from a corridor in the $1980 \mathrm{~s}$ to a hall in the 2010s. In detail:

1.The corridor is the central core space in Japanese nursing homes built before the 2000s; it accounted for $70 \% \sim 80 \%$ in the 1975s 1980s and went down to less than $25 \%$ after the 2000s.

2.The connection corridor started to be core space from the 1995s and increased 
gradually up to $44 \%$ in the 2010 s.

3.The hall space appeared to be core space in all periods, and it became the central core space after the 2010 s, reached $55 \%$.

4. The common facility started to be core space after the 1995 s and reached $28 \%$ in the 2005s.

\section{(1) Corridor core space}

The nursing homes with corridors as core space were mainly built in the 1980s to $1995 \mathrm{~s}$ as large-scale care types. At that time, there was no regulation about unit care type nursing home(Murakami, 2003).

Figure 3(left) is an example of this kind of nursing home built in the year 1982. There is a " $D$ " shape long corridor within the floor; all living rooms and service facilities are allocated to the two sides of the corridor. It is the corridor that became the core space. The SS integration result in the right of the Figure 3 also confirms this conclusion, where the result of integration is coloured based on its value. The high value of well-integrated location to the poor is represented from thick to thin.
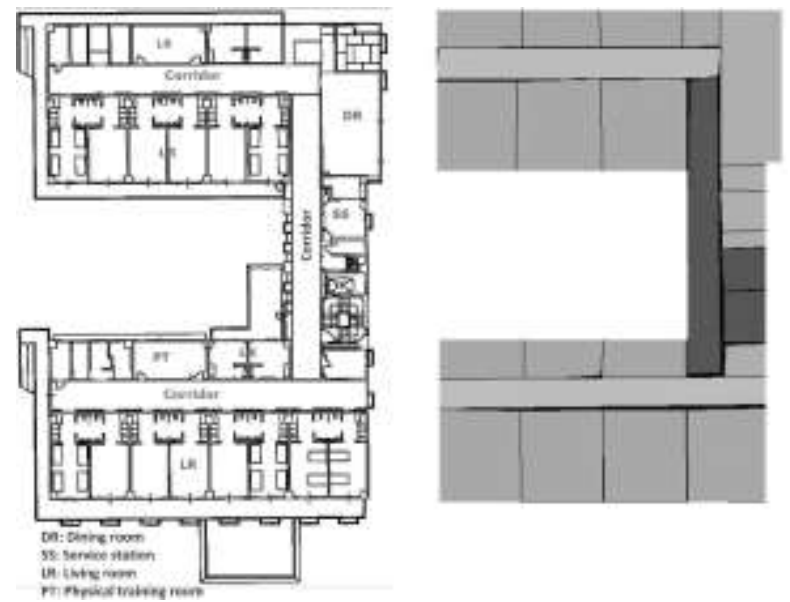

Figure 3: Typical floorplan(left) and integration result(right) of a nursing home with the long corridor as core space

(Source: Created by author)

(2) Connection corridor core space

The nursing homes with connection corridors as core spaces were built after the 1995s and gradually increased.

Figure 4 is an example of this type of nursing home built in the 2005s. There are five care units on the floor, and each has ten private bedrooms. The care units are allocated in three areas and connected by connection corridors. The SS calculation shows that the connection corridor is the core space, as shown in Figure 4(right), where the number in the 
figure is the order from high SS integration to low.
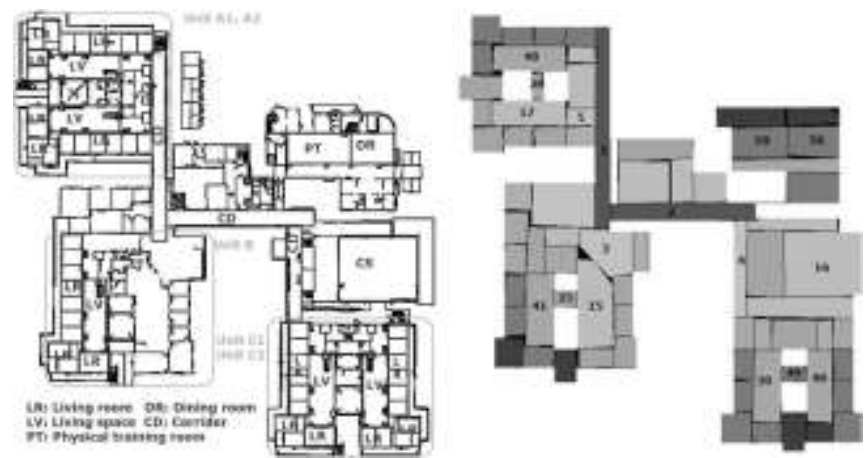

Figure 4: Typical floorplan(left) and integration result(right) of a nursing home with connection corridor as core space

(Source: Created by author)

(3) Hall core space

This type of nursing home appeared in all periods in our investigation and increased after the 2000s when the nursing homes changed to unit care type, reached $55 \%$ in the 2010 s.

Figure 5 is an example of this type of nursing home built in the year 2013. There are five care units and one lounge area on the floor. The lounge is the centre that serves as a connection among each care unit. The SS calculation also confirms the lounge is the core place, as shown in Figure 5(right).

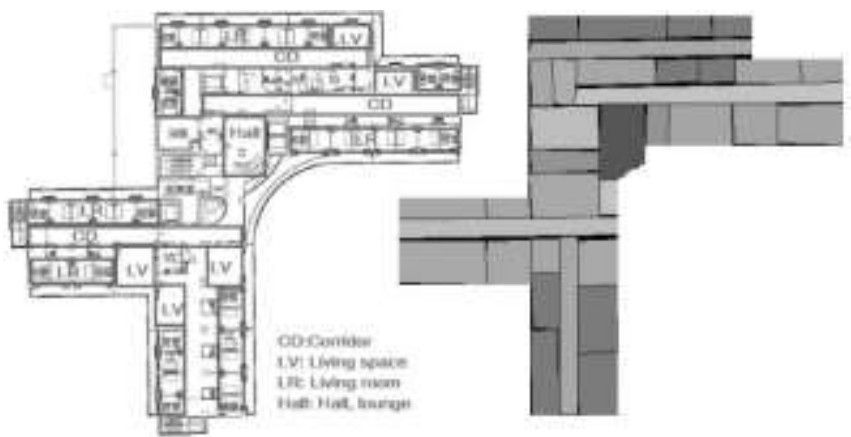

Figure 5: Typical floorplan(left) and integration result(right) of a nursing home with the hall as core space

(Source: Created by author)

(4) Common facility core space

This type of nursing home come out after the 1995s and reached $37.5 \%$ market share in the 2000s. In this type of nursing home, the common facility became more spatially central, 
especially after the 2000s.

The example shown in Figure 6 is a nursing home built in the 2005s, where there are three care units located on the low half side of the site plan; a community space is in the centre. The SS calculation also shows that the community space is the core space.

The other nursing homes in this category also show a similar spatial layout. The shared facility was either allocated in the centre of the site plan or surrounded by different care units.

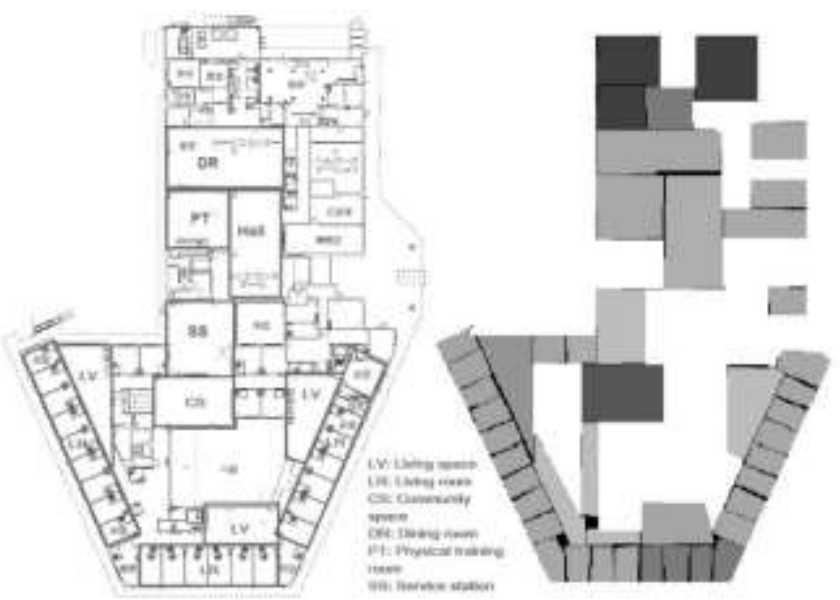

Figure 6: Typical floorplan(left) and integration result(right) of a nursing home with community space as core space

(Source: Created by author)

\subsection{Common core Facility}

Similar to core space analysis, based on the result of the highest spatial integration of shared facilities, we classify nursing homes into the following four core facility types by considering the order of integration.

A. Community space core type, where the community space is core facility.

B. Physical training room core type, where the physical training room is core facility.

C. Service station core type, where the service station is core facility.

D. Dining room core type, where the spatial integration of dining room is the highest in the four common facilities.

\section{(1) Changes over time}

Table 2 and Figure 7 show the number of nursing homes by core facility and distribution over the construction period. 
Table 2: Number of nursing homes by core facility (Source: Created by author)

\begin{tabular}{cccccc}
\hline Build period & CS & PT & SS & DR & Total \\
\hline $1975 s$ & & & 2 & 1 & 3 \\
1980 & & & 8 & & 8 \\
1985 & & & 7 & & 7 \\
1990 & 2 & 2 & 2 & 3 & 9 \\
1995 & 2 & & 7 & 2 & 11 \\
2000 & 2 & & 6 & & 8 \\
2005 & 2 & 1 & 4 & & 7 \\
2010 & 2 & 2 & 4 & 1 & 9 \\
\hline Total & 10 & 5 & 40 & 7 & 62
\end{tabular}

Remark: CS, community space; PT, physical training room; SS, service station; DR, dining room.

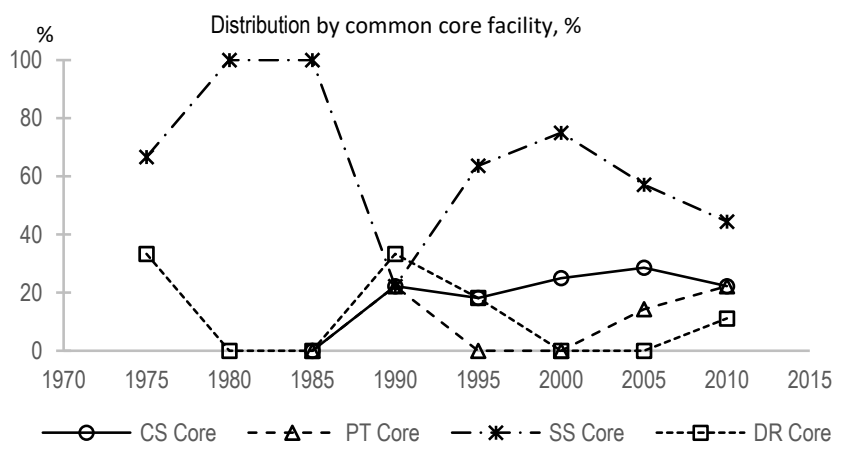

Figure 7: Distribution of nursing home by core facility

(Source: Created by author)

i) Community space core type

There are ten nursing homes in this category. Figure 7 tells that this kind of nursing home commenced in the 1990 s, and it keeps about $20 \%$ of shares up to now.

Table 3 is the floorplan and depth map result of CS core type nursing home. Within this type, many community spaces are allocated in the central part of the floorplan, such as the nursing home $\mathrm{NH} 24, \mathrm{NH} 40$ (large-scale care type), and the nursing home NH 51 (unit care type). Another case is that community space is built as a separate building located either in the central area or a connection point, like the nursing home NH55 in Table 3.

Both of the cases make the community space a high spatial integration place which assures its easier access. 
Table 3: The community core type nursing home floorplan and convex map result (Source: Created by author)

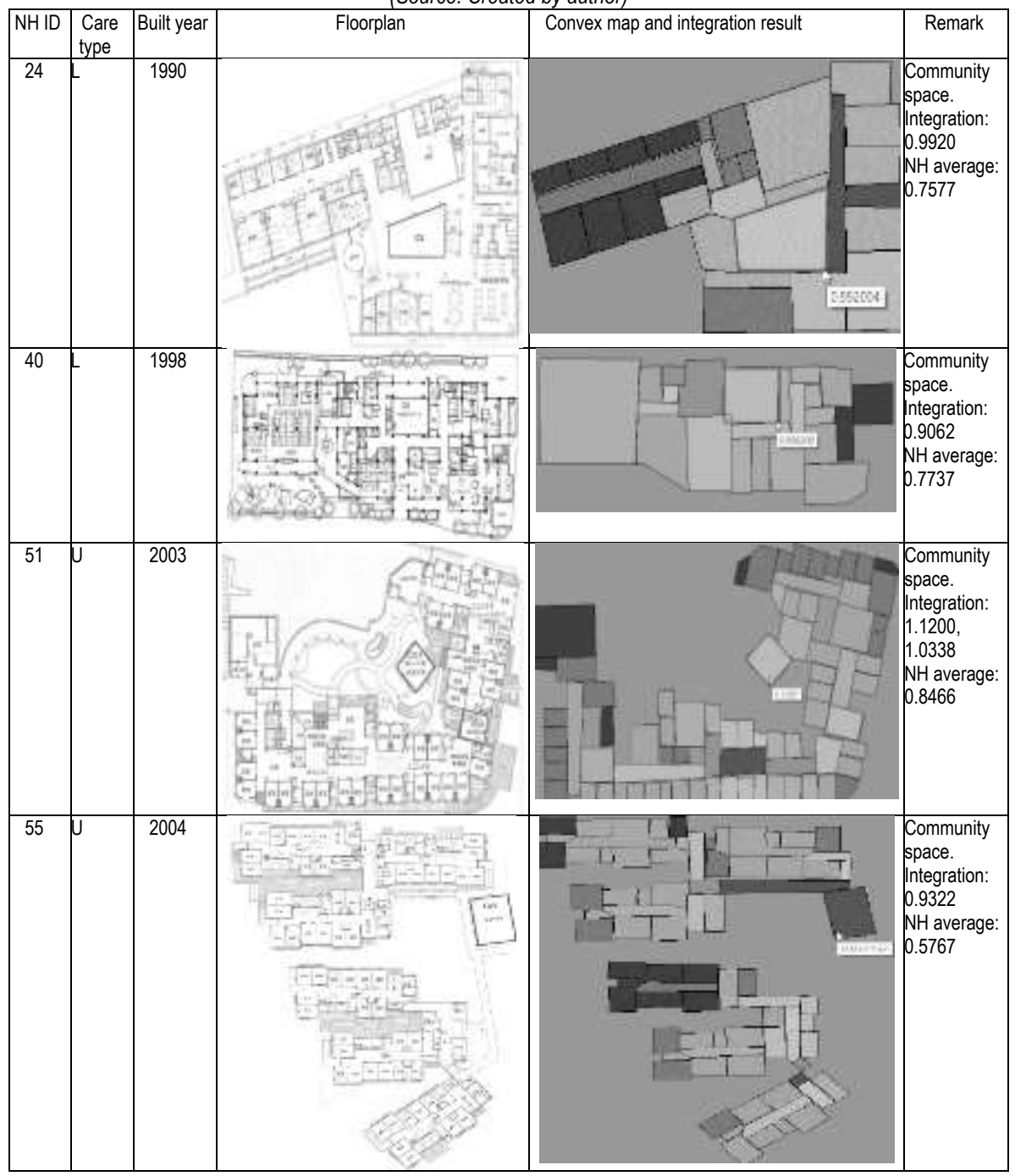

ii) Physical training room core type

In addition to one in the 1990s, the others were built in the 2005s and 2010s. They are one of the modern fashions in nursing homes. Table 4 shows the example of floorplan and convex map result.

The physical training room within this type of nursing home tends to be in the central of 10 
a nursing home, such as the nursing home $\mathrm{NH} 26$ and $\mathrm{NH} 72$. The physical training room in $\mathrm{NH} 26$ is in the topological centre and easy access from the two living areas and the service area. The physical training room in NH72 is also located in the middle of the site plan, making it high spatial integration.

Table 4: The floorplan and convex map results for the nursing home with physical training room as the core type

(Source: Created by author)

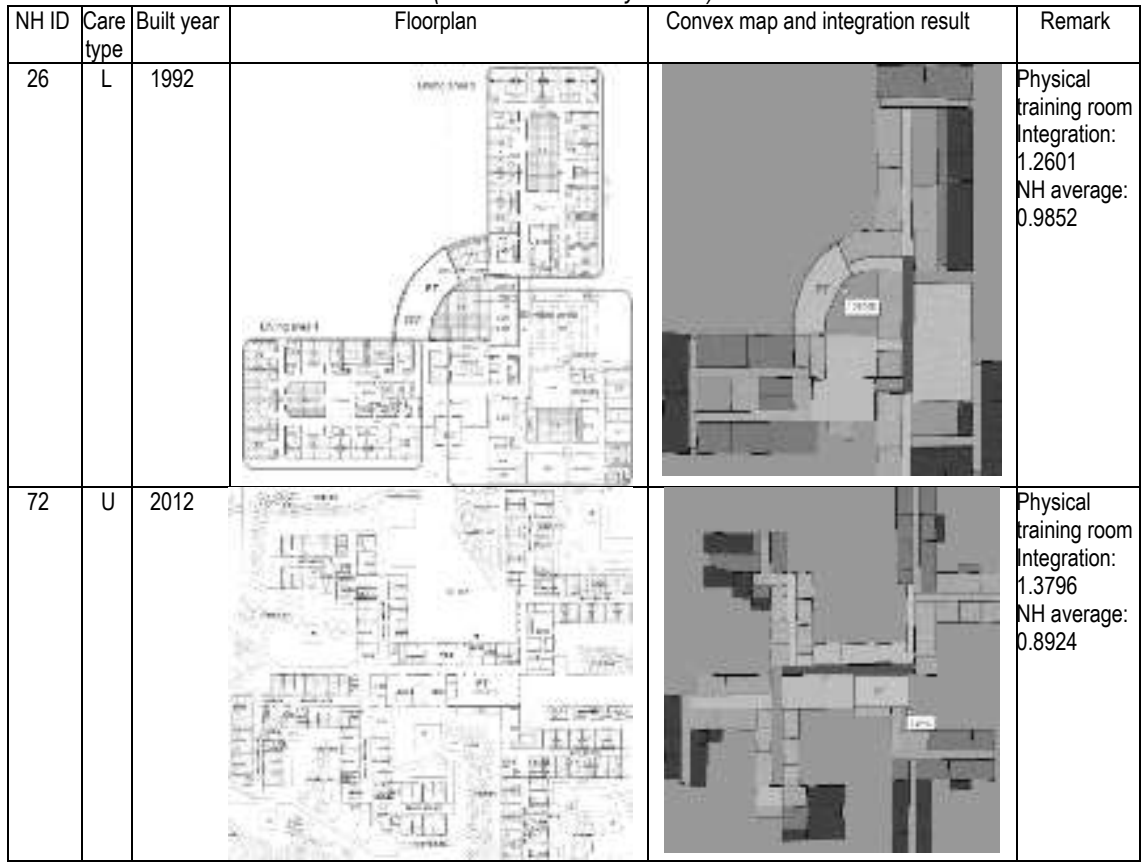

iii) Service station core type

This kind of nursing home was distributed in all periods and is predominant in the 1980s. As the nursing home transferring from large-scale care type to unit care since the 2000s, it declined to about $33 \%$ in the 2010 s.

Table 5 is the floorplan and convex map result for nursing homes where the service station is the core type. The service station in $\mathrm{NH} 11$ and $\mathrm{NH} 32$ is allocated in the geological center of the floorplan. The NH52 and NH61 are two unit-care type nursing homes. Although the service station is not in the geological centre, it has more connections to the surrounding space, making it more spatially integrated. 
Table 5: The floorplan and convex map result of the nursing home with service station as core type (Source: Created by author)

\begin{tabular}{|c|c|c|c|c|c|}
\hline $\mathrm{NHID}$ & \begin{tabular}{|l|} 
Care \\
type
\end{tabular} & Built year & Floorplan & Convex map and integration result & Remark \\
\hline 11 & - & 1982 & 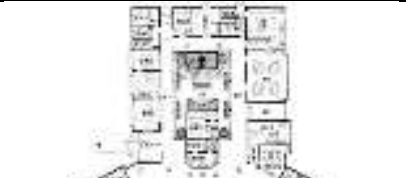 & & \begin{tabular}{|l} 
Service \\
station \\
Integration: \\
1.9041 \\
NH average: \\
1.3352
\end{tabular} \\
\hline 32 & 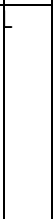 & 1995 & 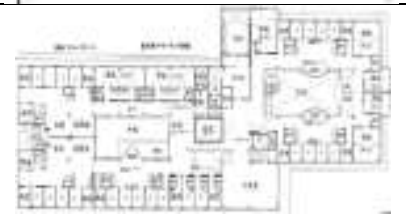 & $\frac{11}{11}$ & \begin{tabular}{|l} 
Service \\
station \\
Integration: \\
1.3475 \\
NH average: \\
0.9021
\end{tabular} \\
\hline 52 & $\mu$ & 2003 & 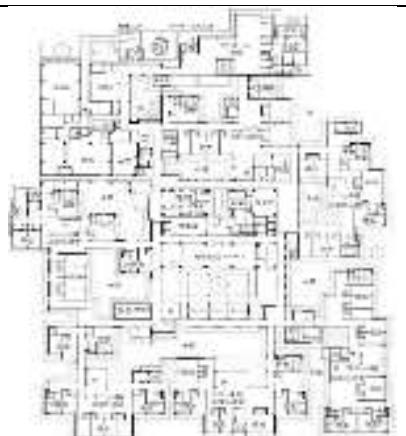 & & $\begin{array}{l}\text { Service } \\
\text { station } \\
\text { Integration: } \\
1.2007 \\
\text { NH average: } \\
0.8796\end{array}$ \\
\hline 61 & $\mu$ & 2005 & 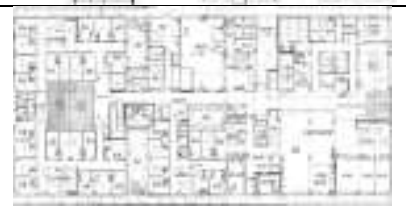 & & $\begin{array}{l}\text { Service } \\
\text { station } \\
\text { Integration: } \\
1.1543 \\
\text { NH average: } \\
0.9310\end{array}$ \\
\hline
\end{tabular}

iv) Dining room core type

There are seven nursing homes in this category, scattered from the 1975 s to the 2010 s.

Table 6 shows two examples of this type. The nursing home NH25 built in the year 1992 has the dining room allocated to the floor centre. The dining room in $\mathrm{NH} 73$ was geologically located on one side, but it has more connections with the surroundings, making it high spatial integration. 
Table 6: The floorplan and convex map result of nursing homes with dining room as core type (Source: Created by author)

\begin{tabular}{|c|c|c|c|c|c|}
\hline NH ID & $\begin{array}{l}\text { Care } \\
\text { type }\end{array}$ & Built year & Floorplan & Convex map and integration result & Remark \\
\hline 25 & $\mathrm{~L}$ & 1992 & 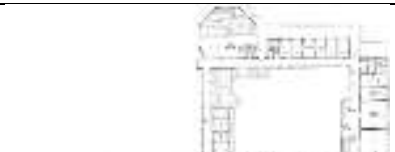 & 17 & $\begin{array}{l}\text { Dining room } \\
\text { Integration: } \\
1.5895 \\
\mathrm{NH} \text { average: } \\
0.9841\end{array}$ \\
\hline 73 & $\bar{U}$ & 2012 & 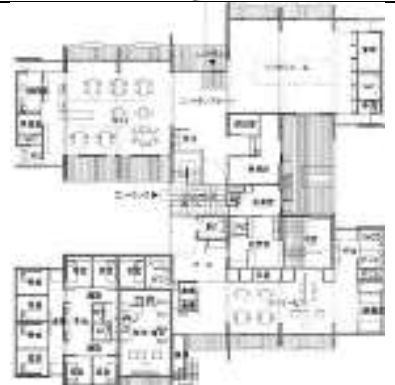 & $-7 \quad 1$ & $\begin{array}{l}\text { Dining room } \\
\text { Integration: } \\
1.4745 \\
\text { NH average: } \\
0.9185\end{array}$ \\
\hline
\end{tabular}

\section{(2) Comparison by nursing home care type}

Figure 8 is the distribution of nursing homes in each common core facility type; Figure 9 is the average integration of the shared facilities in each care type.

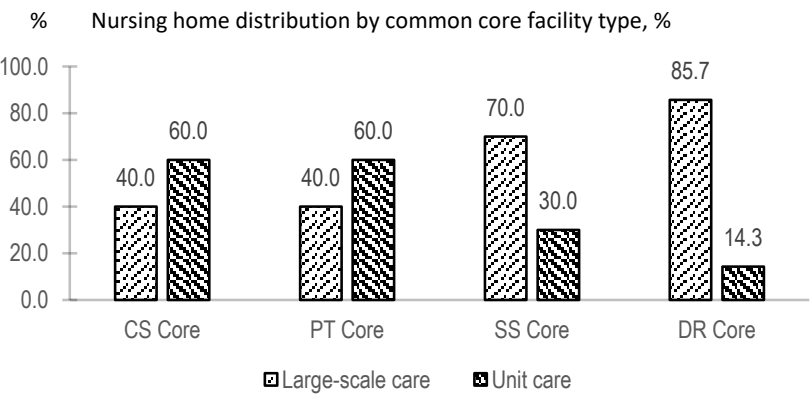

Figure 8: Nursing home distribution in each common core facility type

(Source: Created by author)

Compared with the large-scale care type in Figure 8, there are more unit care nursing homes where the community space and physical training room are the common core 
facilities, which accounted for $60 \%$ respectively in both groups. It means the community space and physical training room have become the space with more spatial centrality in modern unit care nursing homes. On the other hand, the large-scale type nursing homes are predominant in taking service station and dining room as common core facilities.

Figure 9 shows that the spatial integration of averaged common core facilities increased in unit care types. It means these common facilities, especially community space and physical training room, have become the spatial centrality in modern unit care nursing home spatial layout design.

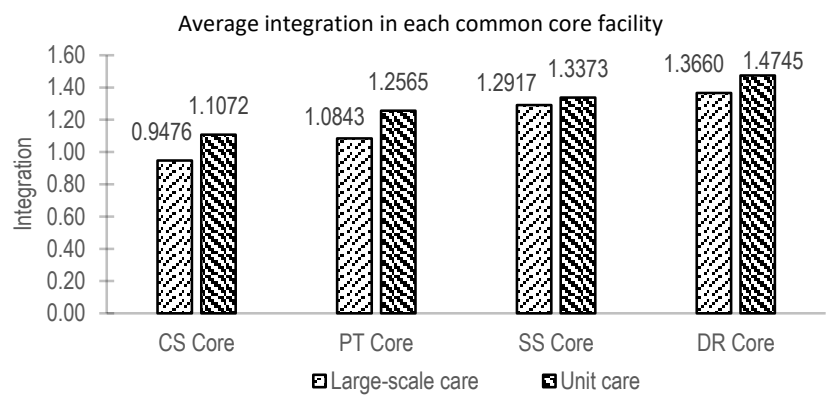

Figure 9: Average integration in each core facility

(Source: Created by author)

\subsection{Conclusion}

The spatial characteristics of 62 Japanese nursing homes by space syntax theory clarify the core space has been changed from the corridor in the 1980s to the hall space nowadays in Japanese nursing homes. In detail:

(1) Most of the large-scale care type nursing homes were designed with a long corridor or main corridor. Investigation shows this corridor is core space in $70 \% \sim 80 \%$ of nursing homes built in the 1975s 1980s, and this number got down since then, reached to less than $25 \%$ after the 2000 s.

(2) As the nursing home transferring from large-scale care type to unit care type, the spatial layout also changed. The structure of multiple care units connected with the connection corridor caused the connection corridor to be the core space in the unit care type nursing homes, it accounted for $40 \%$ of nursing homes built in the 2010 s.

(3) The lobby, entrance hall, lounge, etc., hall space has been the core space in all construction periods. The number of nursing homes belongs to this core space type was gradually increased after the 1990s, and it became the main spatial structure in the 2010s by accounting for $55 \%$ in total.

(4) The community space, physical training room, service station, and dining room, etc., common facilities started to be core space after the 1995s. There was an uptrend in the 2000 s which reflects the changes of the shared facility in modern nursing home spatial layout design. 
About the spatial characteristics of shared facilities, analysis shows:

(1) The service station was the shared core facility in almost all nursing homes built in the 1980s and 1985s, but the proportion went down in nursing homes built after the 2000s, reaching $33 \%$ in the 2010 s.

(2) The community space began to emerge as common core facilities from 1990 and kept its shares of about $20 \%$ until 2010 . Besides, the physical training room also appeared to be the core facility in some nursing homes built after the 1990 s. It accounted for $22 \%$ in the 2010s.

(3) Comparing core public facilities in large-scale care type and unit care type shows that more unit care nursing homes have community spaces and physical training rooms as common core facilities, accounting for $60 \%$ each. Moreover, comparing the average spatial consolidation of the two care types of nursing homes indicates that spatial consolidation of common core facilities has increased for the unit care type of nursing homes. Both results disclose the importance of community space and physical training rooms in modern nursing home spatial design.

\section{Acknowledgement}

This research is partially supported by a grant from the TRA program of the first author's PhD study at the Tokyo Institute of Technology.

\section{Note}

1) The nursing homes were selected from the following Japanese architecture publications:

Data File of Arch. Design and Detail, Vol.3, Dec. 1983

Data File of Arch. Design and Detail, Vol.34, Sep. 1991

Data File of Arch. Design and Detail, Vol.71, June 1999

Data File of Arch. Design and Detail, Vol.103, Nov. 2011

Shinkenchiku Vol.3,1980

Shinkenchiku Vol.12,1982

Shinkenchiku Vol.6,1983

Shinkenchiku Vol.6,2001

Shinkenchiku Vol.4,2004

Shinkenchiku Vol.10,2011

Shinkenchiku Vol.10,2012

Shinkenchiku Vol.12,2014

Contemporary Archi.Vol.3,2006

Contemporary Archi.Vol.2,2014

\section{References}

Daniel K. et. al.(2013), Syntactic Resilience, Proceedings of the Ninth International Space Syntax Symposium, pp.054:1.

Dawes M. et. Al.(2013), Precise locations in space: An alternative approach to space syntax analysis using intersection points. Architecture Research, 3(1). pp.1-11. 
Dettlaff Weronika(2014), Space Syntax Analysis - Methodology of Understanding the Space, Ph.D. Interdisciplinary Journal, pp.283-291.

Hillier B.(1996), Space is a machine, Cambridge University Press, p.246.

Inoue M.(1990), A study on common facility planning in the paid nursing home, Shimizu Corporation Research Report, No.51, pp.83-94.

Kan S.(2012), Spatial analysis and application study on medical and welfare facilities - a case study of space syntax and isovist, Kobe University.

Kato Y.(2007), Environmental Behavioral Study on Space Creation in Elderly Facilities, University of Osaka, Ph.D. dissertation.

Klarqvist B.(1993), A space syntax glossary(Electronic version). Nordisk Ar-kitekturforskning, No.2, pp.11-12.

Koike S., Nakagawa O.(2011), Using Space Syntax to Clarify Spatial Configurations In Japanese Public Museums, J. Archit. Plan., AIJ, 76(662), pp.851-857.

Kozuma T. et al.(2015), An investigation on the conversion of behavior in semi-public space: studies on the revision in the nursing home as the nursing care level of dwellers grow severe, part 2. Proceedings of Architectural Institute of Japan(Kanto).

Mori K.and Kitaguchi Y.(2014), Analysis of the present condition of garden and dining room in assisted living-A study on common areas of assisted living vol.1, Proceedings of Architectural Institute of Japan(Kinki).

Mori S.(2004), A study on elderly living facilities from the viewpoint of living improvement, Nagoya University, Ph.D. dissertation.

Murakami M. et al(2003), Transition of Institutional Formation and the Principle of Nursing in Elderly Welfare - From a Large Group Care to a Small Group Care -, Tokai University, No.9, pp.89-95.

Nes Akkelies(2011), The one and two-dimensional isovists analyses in Space Syntax, IOS Press, Amsterdam, pp.163-183.

Peponis J. and Wineman J.(2002), Spatial Structure of Environment and Behavior. In: R. Bechtel and A. Churchman (Edition), Handbook of environmental psychology. John Wiley and Sons, Inc. New York.

Takano Yu., et al.(2010), Trends and Prospects of Urban Space Structure Research Using Space Syntax, Landscape, and Design Research Lecture Collection, No. 6, pp.183-190.

Toyama T.(2002), A Study on the Introduction of Private Rooms and Small Care Units at Long-Term Care Insurance Facilities, Medical Economics Research, No.11, pp.63-89.

Ueno J., Kishimoto T.(2008), An Analysis of Pedestrian Movement in Multilevel Complex by Space Syntax Theory - In the case of Shibuya Station, Journal of the City Planning Institute of Japan, No.43-3, pp.49-54.

Varoudis T.(2013), Space Syntax Angular Betweenanes Centrality Revisited. Proceedings of the 9th International Space Syntax Symposium, pp.057:7. 